\title{
OS KAINGANG DO IVAÍ, SUAS DANÇAS E A EDUCAÇÃO INTERCULTURAL
}

\author{
THE KAINGANG OF IVAÍ, THEIR DANCES AND CROSS-CULTURAL EDUCATION
}

LOS KAINGANG DEL IVAÍ, SUS BAILES Y LA EDUCACIÓN INTERCULTURAL

Juliana Dias Boaretto*, Giuliano Gomes de Assis Pimentel*

\section{Palavras-chave} Cultura. Dança. Ensino. População indígena.
Resumo: Discutimos a dança da etnia Kaingang, na perspectiva da educação intercultural, na busca de contribuir com a efetivação da lei 11.645/08. A pesquisa foi desenvolvida com o grupo Kakrēkin, da terra indígena Ivaí-PR, com uso de observação direta, entrevistas, filmagem e fotografia. Para análise foi utilizada a Técnica de Análise de Conteúdo Temático. A dança na comunidade ocorre como uma forma de educação Kaingang e, por sua vez, é fortalecida em suas tradições. No processo de disseminação da cultura indígena, a educação intercultural apresenta-se como uma forma de contribuir para a Educação Física Escolar e demais áreas.

Abstract: We discuss Kaingang dance under the perspective on cross-cultural education, in order to contribute to the enforcement of law 11645/08. The research was conducted with the Kakrēkin group from the Ivaí-Paraná indigenous land, using direct observation, interviews, film and photography. The analysis used the Thematic Content Analysis technique. Dance in the community is a form of Kaingang education while it is strengthened in their traditions. In the process of dissemination of indigenous culture, intercultural education contributes to the school Physical Education and other areas.

Resumen: Discutimos la danza de la etnia Kaingang, desde la perspectiva de la educación intercultural, para contribuir con la efectivación de la ley 11.645/08. La investigación fue desarrollada con el grupo Kakrēkin, de la tierra indígena Ivaí-Paraná, con uso de observación directa, entrevistas, filmación y fotografía. Para el análisis fue utilizada la Técnica de Análisis de Contenido Temático. La danza en la comunidad es realizada como una forma de educación Kaingang y, al mismo tiempo, es fortalecida en sus tradiciones. En el proceso de diseminación de la cultura indígena, la educación intercultural se presenta como una forma de contribuir con la Educación Física escolar y otras áreas.
*Universidade Estadual de Maringá. Paranavaí, PR, Brasil.

E-mail: julivictor@yahoo.com.br

Recebido em: 03-11-2014

Aprovado em: 21-03-2015

(c) (1) \&) Licence 


\section{INTRODUÇÃO'}

Analisamos, na perspectiva da educação intercultural, o desenvolvimento de danças da etnia Kaingang no seu processo de disseminação cultural. Tal estudo se justifica por trazer informações contemporâneas sobre a etnia, dada a dificuldade em encontrar materiais sobre a cultura corporal dos povos indígenas. Com a Lei 11.645/08, essa lacuna se agrava, pois se determina a obrigatoriedade da inclusão, nos currículos escolares, do ensino da História e Culturas Afro-brasileiras e Indígenas. Em geral, após o reforço da lei, acreditamos que aumentou a demanda das escolas por este conhecimento.

Após levantamento em 30 Terras Indígenas (TI) do Paraná ${ }^{2}$, identificamos o grupo de dança Kakrēkin na TI Ivaí, situada nos municípios de Manoel Ribas e Pitanga. O diferencial do grupo é que desenvolve a dança Kaingang como forma de avivamento das tradições e educação dos jovens na comunidade, com apresentações tanto em TI quanto em cidades. Após autorização e aproximadamente dois anos de pesquisa em campo com os Kaingang do Ivaí, foi entregue aos coordenadores do grupo Kakrēkin, José Carlos e Adalton, um roteiro para a realização dos registros. A coleta ocorreu em local ritual, próximo à natureza e afastado da aldeia.

Durante as coletas, foram utilizados recursos audiovisuais para melhor captar as respostas, bem como apreciar detalhes expressos pelos participantes no momento da transcrição e anotações em diário de campo. As transcrições foram abordadas, em partes, selecionando conteúdos que se aproximavam do objetivo da pesquisa com o intuito de dialogar a fonte oral com fontes encontradas na literatura. Para o procedimento de análise dos dados, numa perspectiva empírico-analítica de ciência, utilizou-se a Técnica de Análise de Conteúdo Temático desenvolvida por Richardson (2011). A pesquisa foi aprovada pelo parecer $n$. 581/2009. Ao dialogar com os Kaingang na perspectiva intercultural, foi possível descrever 0 discurso social a partir do contato direto com o objeto estudado.

A abordagem do estudo é pela educação intercultural. Educar nessa perspectiva denota foco na promoção do diálogo e do intercâmbio "entre diferentes grupos, cuja identidade cultural e dos indivíduos que os constituem são abertas e estão em permanente movimento de construção, decorrentes dos intensos processos de hibridização cultural" (CANDAU, 2006, p. 102).

Na discussão, organizamos o texto com: uma breve contextualização sobre os Kaingang do Ivaí; o desenvolvimento das danças na TI Ivaí; e a contribuição da educação intercultural no processo de disseminação da cultura indígena.

\section{UMA BREVE INTRODUÇÃO: OS KAINGANG DO IVAÍ}

No Paraná há três etnias indígenas: Guarani, Kaingang e Xetá. A etnia Kaingang representa a terceira em população no Brasil, fala a língua do tronco linguístico Jê e encontrase distribuída em quatro estados brasileiros: São Paulo, Paraná, Santa Catarina e Rio Grande do Sul (HENNERICH, 2007), em mais de 30 Terras Indígenas (TI). Não obstante, cada uma

10 artigo está baseado na dissertação elaborada pela autora, sob orientação do coautor, e apresentada ao Programa Associado de PósGraduação em Educação Física - UEM/UEL, para fins de obtenção do título de mestre. 
dessas TI tem suas heterogeneidades, estrutura social e princípios cosmológicos Kaingang que continuam vigorando, atualizados frente às diferentes conjunturas históricas (MOTA, 2009, INSTITUTO SOCIOAMBIENTAL, 2003).

Na bacia do rio Ivaí há três $\mathrm{TI}^{3}$, onde vivem em torno de 2.500 Kaingang e algumas famílias da etnia Guarani, as quais já ocupavam tradicionalmente esses territórios (MOTA; NOVAK, 2008). A TI Ivaí conta com uma população aproximada de 305 famílias, totalizando 1.470 moradores Kaingang. A área da $\mathrm{TI}$, que já foi de 36.000 ha aproximadamente, foi reduzida para 7.200 ha com o acordo de 12 de maio de 1949 (MOTA; NOVAK, 2008). Ainda assim, sua regularização só foi homologada pelo decreto ํㅜ. 377 de 14/04/91, e demarcada administrativamente (DOU, 26/12/91), Reg. CRI em Pitanga, Comarca de Laranjeiras do Sul (3.652 ha). Matr. 17.489, Liv. 2 RG, fl. 1, em 07/02/92. Reg. CRI de Manoel Ribas, Comarca de Ivaiporã (3.654 ha), Matr. 25.752, s/ Liv., fl. 01. Reg. SPU Cert. 10, em 02/08/94 (MOTA; NOVAK, 2008).

Em nossa primeira viagem à TI Ivaí, em 2010, as lideranças presentes no momento da pesquisa eram o cacique, Sr. Ivo Borges, e o vice-cacique, Sr. Domingos Crispim. A este último foi dada a incumbência de prestar informações e nos guiar pela comunidade, o que legitimava nossa presença ali e reafirmava o status da autoridade instituída.

A partir das imersões na TI Ivaí, identificamos os pontos de referência do que seria o núcleo geopolítico da aldeia: o Posto da FUNAI, a Unidade de Saúde da FUNASA, a Casa de Liderança, duas escolas (municipal e estadual), um telefone público situado em frente à escola, uma Igreja Católica (Capela Nossa Senhora do Guadalupe), um campo de futebol, uma extensa churrasqueira, um salão de baile e uma cadeia (utilizada em casos de desavenças graves, adultério, alcoolismo e assassinatos). Ao redor desse centro existem residências familiares, geralmente habitadas, segundo Sr. Domingos, por quem faz parte da liderança ou por aqueles que são indicados para ocupar os postos de trabalho assalariados da aldeia (motorista, professor, agente sanitário, agente de saúde, professor, tratorista, entre outros).

A TI Ivaí possui plantações de arroz, feijão, milho, batata-doce e mandioca. A respeito da alimentação, o vice-cacique relata que atualmente são poucos os Kaingang que plantam e colhem seu alimento. Em alguns momentos torna-se necessário a compra ou a troca do produto entre eles. Faustino (2006) destaca que, com a redução das terras e o aldeamento, a agricultura familiar e as roças comunitárias, organizadas pela FUNAI, são, atualmente, no Ivaí, as principais fontes de sobrevivência do grupo. De acordo com Mota (2003), o diagnóstico etno-ambiental da TI Ivaí, compreendido entre 2002/2003, evidenciou que o solo da aldeia está desgastado e depois de uma ou duas colheitas consecutivas a produtividade fica comprometida e a FUNAI não tem verbas e nem pode contar com pessoal especializado para promover a melhoria da qualidade do solo. 0 que restou das terras é uma reduzida parte do que os Kaingang tinham no passado.

Tommasino e Fernandes (2003) evidenciam serem os Kaingang um povo que tradicionalmente vivia da caça, coleta e agricultura e que, no tempo presente, tem na agricultura o elemento básico de sua economia. Neste sentido, vivem das roças administradas pela FUNAI, das roças familiares, da venda de artesanato, de assistência e de serviços rurais temporários. Na TI Ivaí, observamos, em algumas casas, mulheres e crianças confeccionando cestas, balaios e outros utensílios. A confecção do artesanato também é uma atividade familiar, 
sendo que os homens ocasionalmente ajudam na retirada e transporte da taquara do mato até sua casa e acompanham suas mulheres à cidade no momento da comercialização.

Rotineiramente os homens trabalham na roça e retornam aproximadamente às 17h; mulheres ficam em casa fazendo artesanatos e as crianças ficam na escola (TI Ivaí); em seu tempo livre, se organizam para jogar bola no campo, conforme foi possível ser observado. Já os adultos se reúnem nos finais de semana para realizarem a prática do futebol. Quando se trata de outras atividades, durante a noite, alguns Kaingang descansam, outros conversam com famílias e/ou amigos, tomam chimarrão, assistem novela e jornal na televisão, e, quando possível, acompanham campeonatos de futebol. Uma característica cultural é a coexistência de práticas ancestrais com outras atualizadas e ressignificadas.

Muitos grupos familiares Kaingang passam grande parte do tempo do lado de fora das casas, ao lado dos fogos onde realizam a maior parte das atividades diárias. Neste lugar conversam, tomam sol, observam as crianças pequenas, recebem os parentes e afins, confeccionam o artesanato e preparam os alimentos. Mesmo as famílias que têm acesso às casas de alvenaria e fogão a gás, quando podem, constroem, nos fundos ou ao lado, suas in onde preferem morar os mais velhos (FAUSTINO, 2006, p. 180).

Sobre algumas atividades de esporte e lazer, pode-se observar que a TI Ivaí é um local com um extenso espaço para as práticas corporais. Dentre os esportes, o que mais se destaca é o futebol, prática presente tanto para homens, mulheres e crianças, havendo 12 times masculinos e aproximadamente oito femininos. O professor da disciplina de Educação Física (não índio) auxilia, em alguns momentos, nos treinos de futebol e na organização de viagens para levar as equipes para participarem de campeonatos com a participação de indígenas e não indígenas. Cada time masculino tem seu próprio nome e sempre há um líder indígena presente em cada equipe. Alguns torneios de futebol acontecem na TI Ivaí, o que, segundo Sr. Domingos, evoca reciprocidade da visita.

Dentre as práticas corporais, a dança também é entendida como elemento cultural de cada etnia e não está desvinculada da realidade concreta ora sumarizada neste tópico. Portanto, a dança assume sentidos e significados relevantes para a preservação e ressignificação do modo de ser Kaingang, mas é também determinada por essas condições materiais. Neste estudo enfatizamos tal manifestação como forma de educação intercultural.

\section{O DESENVOLVIMENTO DAS DANÇAS NA TERRA INDÍGENA IVAÍ}

A dança é desenvolvida na comunidade pelo grupo Kakrēkin-Tamanduá sob a coordenação de dois professores: José Carlos e Adalton 4 . Para conhecer a prática da dança, Adalton buscou nas pessoas mais velhas, "os mais experientes", 0 entendimento de seus valores e os movimentos da dança. Enfatiza que, com dificuldade, conseguiu revitalizar oito danças de sua cultura. A partir desse conhecimento adquirido, o grupo passou a se encontrar durante a semana para ensaiar. Adalton diz que o grupo teve início com poucas pessoas, mas "hoje passa de 70 participantes". Em relação às danças praticadas na TI Ivaí, antes de começar o grupo, elas já foram praticadas em muitos momentos na comunidade e fora dela. No tempo presente, são mais convidados para participarem de eventos em comemoração ao Dia do Índio (19 de abril).

4 Na primeira entrevista em maio de 2010, apenas o professor Adalton desenvolvia as danças na comunidade e, após a eleição do novo cacique, se decide politicamente atribuir a José Carlos a liderança do grupo. Porém, mesmo não sendo mais o líder do grupo, Adalton continuou ensinando e auxiliando o novo líder. 
Nos encontros para ensaios, no galpão da comunidade, é recorrente a presença de uma pessoa mais velha para passar os conselhos e acrescentar novos conhecimentos. Segundo Adalton, o grupo visa retomar as danças para revitalização do sentido ritualístico, abarcando a dimensão do mito, do ser Kaingang, do espírito Kaingang como o que está presente na dança do Tamanduá. Neste sentido, a dança é uma possibilidade de educar-se ${ }^{5}$ como Kaingang.

Quando nos foi permitido conhecer e registrar as danças, fora do núcleo territorial da aldeia, três delas foram analisadas: Kakrēkin - Tamanduá; A mý há - Boas vindas; Vēnh so há to venh grén - Dança do amor. Para o presente artigo, além de descrever o desenvolvimento da dança na comunidade, em alguns momentos citaremos a dança do Tamanduá. Esta dança dá o nome ao grupo, dada sua importância ritual:

[...] a dança do Tamanduá que foi uma dança dos guerreiros né, que os índios consideram o Tamanduá como um...o bicho mais forte que existe né...fora $0 . . .0$ tigre que tem né, a onça que tem né. Então, o Tamanduá por causa do...como é que é?...das garras dele né...então eles matam esse Tamanduá...esse Tamanduá pra...pra fazer tipo um remédio pra eles saírem em combate de uma guerra (10/05/2010, Adalton, TI Ivaí).

As guerras aconteciam a partir de compromissos assumidos pelos guerreiros para defender sua aldeia e, antes de saírem, realizavam a dança e consumiam a essência do Tamanduá, como ilustra a letra do canto que acompanha a dança: Kakrēkin, Kakrēkin Tamanduá, Tamanduá; Inh mý ã tara nīm - Dai-me a sua força; Inh mý ã tara nīm - Dai-me a sua força.

Adalton relata que os guerreiros pedem para o espírito do Tamanduá transferir, de forma sobrenatural, seus poderes. O momento místico se manifesta quando os guerreiros invocam o espírito do Tamanduá e no movimento se abaixam para o Pajé sair caminhando com o seu chocalho em volta do círculo. A dança apresenta a retomada de um ritual místico, ou seja, o espírito do Tamanduá está sendo incorporado e levantado na própria representação da dança, o que nos possibilitou observar o mito do Tamanduá presente neste momento. De acordo com Grando (2004), durante os rituais indígenas esses momentos são meios de interação entre 0 mundo dos espíritos e o mundo real.

Para a realização dessa dança, Adalton elucida que todos os guerreiros que se preparavam para ir à guerra tinham que levar suas esposas para participarem da dança. Assim, "as mulheres ingressam nessa dança porque, para os guerreiros, esse poderia ser o último momento junto com elas". Como podemos interpretar a partir de relatos de rituais, como o do Canjire (FASSHEBER, 2010), a mulher exerce simbolicamente um fator protetor dos homens em combate. No dia em que conhecemos as danças, Adalton destacou que somente algumas mulheres eram esposas de seus parceiros. Por outro lado, quando o grupo dançava para nós, a comunidade estava presente, denotando que, independente de algumas mudanças, essa prática ainda é gregária.

As danças ocorreram ao ritmo do líder do grupo - que utilizava um chocalho confeccionado por ele -, pelo canto e por meio da marcação firme dos pés. Os movimentos corporais são criações e reproduções das diversas vivências pelo modo de vida dos Kaingang, as quais representaram emoções, desejos, fortalecimento do espírito para quem vai sair em

50 entendimento de educação adotado no texto enfatiza a transmissão de conhecimentos filosóficos, éticos e científicos, modos de ser e sentir e do patrimônio cultural de forma sistematizada e visando dotar o participante de ferramentas e significados para atuar como sujeito de sua própria cultura, bem como dominar elementos universais da Humanidade. 
defesa da sua comunidade, relações familiares, relações com o "outro", revelando, em cada uma, a construção histórica do ser Kaingang.

Como explica Lara (2008), é no momento da dança que as pessoas podem estabelecer 0 seu próprio modo de existência, bem como o de viver e de ter o contato com o mundo, renovando-o. Consequentemente "têm a possibilidade de efetivar todas as interações possíveis, intensificando as relações sociais, as criações, o potencial comunicativo, retornando ao tempo sagrado e à experiência do mito" (LARA, 2008, p. 45).

Para os Kaingang, o papel da dança enquanto ritual vem na perspectiva da (re)criação da tradição, na qual o mito e a história são revitalizados e ressignificados para educar o corpo e a identidade específica dos Kaingang, a qual corrobora Mauss (1999), ao descrever que as maneiras de transmissão das técnicas corporais possibilitam a criação e recriação das danças, que serão sempre tradicionais, mesmo que estas tenham outras experiências ao terem contato com outras culturas. Essas experiências, como cita Grando (2004, p. 246) em sua pesquisa:

[...] podem inspirar a criação de coreografias, assim como os sonhos e outras formas de conhecer a realidade se expressam em movimentos que simbolizam essa compreensão. A pessoa quando dança comunica-se com o grupo a que pertence ao mesmo tempo em que se comunica com as outras dimensões de seu mundo e, nesse processo, educa-se como pessoa, socialmente identificada com seu grupo de idade, sexo, clã e etnia [...].

Mesmo havendo experiências dentro e fora da comunidade, os Kaingang não mudam 0 fato de aprenderem com os mais velhos e de vivenciarem suas danças tradicionais, que vão sendo conhecidas a cada dia, o que nos levou a refletir sobre o processo dinâmico nas comunidades indígenas. Como vimos em Mauss (2003, p. 115), "quando uma geração passa a outra a ciência de seus gestos e de seus atos manuais, há tanta autoridade e tradição social como quando essa transmissão se faz pela linguagem". Os movimentos vivenciados por meio da dança expressam todo um ritual e demonstram o espírito guerreiro de ser Kaingang.

Em nossa análise, dançar, para o Kaingang, é um momento de união, de fortalecimento do espírito da comunidade e, ainda, uma forma de sair em sua defesa. A guerra agora é especialmente para afirmar-se como portador de cultura "pura" frente ao outro, o Fóg. Enquanto o futebol (às vezes uma guerra ritual) serve para demonstrar que o Kaingang é forte até na atividade agonística do Fóg, a dança mostra que não perde sua cultura (PIMENTEL; UEMA; OLIVEIRA, 2013). Não por menos, apesar da ressignificação/revitalização desse ritual Kaingang pela dança, o grupo se retroalimenta internamente do conjunto de práticas e representações arcaicas dadas no ritual.

Porque a dança age nesse diálogo interno e externo da TI, que retomamos a questão do diálogo intercultural. A partir de Bergamaschi e Gomes (2012) ponderamos sobre o desafio à escola que é conviver e efetuar trocas com as sociedades indígenas. Considerando a experiência Kaingang em combater a invisibilidade histórica de forma dinâmica e dialógica, temos um norte para não produzir "índios genéricos" e anacrônicos:

Apesar da colonização, do genocídio, da exploração, da catequização, da tentativa de assimilar os indígenas à sociedade nacional, estes povos mantiveram-se aqui, resistentes, mesmo que por vezes silenciosos. No entanto, se apresentam fortes, num movimento político de afirmação étnica, mostrando que aqui estão e permanecerão. No contato, a todo o momento são postos à prova quanto as suas identidades étnicas, visto que a concepção que predomina nas sociedades não indígenas é de 
povos do passado, não compreendendo que a dinâmica cultural, que é própria de todas as sociedades, faz com que incorporem alguns elementos da cultura ocidental, o que não significa que deixaram de se identificar como indígenas (BERGAMASCHI; GOMES, 2012, p. 55).

Ao conhecer as danças e seu desenvolvimento na comunidade por suas lideranças José Carlos e Adalton, observamos que tal processo permitiu uma ressignificação a partir da relação entre elementos e valores tradicionais e modernos. Destarte, compreende-se que elementos da tradição não são totalmente abandonados, mas, sim, que a estes são incorporados elementos característicos da modernidade por meio da hibridação cultural. Ou seja, em todos os lugares aonde chega a modernidade, ocorre hibridação, pois esta não rompe o que era tradicional, mas insere-se mesclando características e fazendo a justaposição de diferentes temporalidades, artefatos e lugares (CANCLINI, 2006).

Assim, ao descrever o desenvolvimento da dança na TI Ivaí, mesmo que de maneira sintetizada, foi documentada uma forma de organização do próprio Kaingang. Neste sentido, a dança para eles não se dá apenas nos registros, mas também nas vivências cotidianas, no processo desse grupo em revitalizar danças de sua tradição cultural. Logo, se manifesta como um jeito de fazer, buscar e revigorar a memória de como se é ser Kaingang e, ao fazer isso, os professores José Carlos e Adalton traçam um caminho, um jeito de buscar essas informações para serem produzidas e manifestadas nas danças tradicionais Kaingang.

As informações pesquisadas e as relações interculturais vivenciadas no estudo apresentam possibilidades de conhecer um pouco mais sobre os Kaingang pertencentes à TI Ivaí, onde foi possível perceber suas lutas e a busca de sua autoafirmação enquanto povo que luta para manter sua cultura em movimento.

\section{DANÇAS DOS KAINGANG DO IVAÍ E O (RE)PENSAR PARA UMA EDUCAÇÃO INTERCULTURAL}

[...] quando rejeitamos a história única, quando nos apercebemos que nunca há uma história única em nenhum lugar, reconquistamos o paraíso. (Chimamanda Ngozi Adichie $^{6}$

Ao relatar sobre os Kaingang do Ivaí e por meio das coletas realizadas com os povos indígenas no Paraná, algumas descaracterizações ocorreram por compreender que não existe uma "história única". Pelo contrário, vivenciamos e pesquisamos algumas etnias e como elas diferem entre si. Ao relacioná-las aos conteúdos estudados na escola sobre os povos indígenas, refletimos os equívocos que ocorrem nesse ambiente quando estes não acompanham saberes na contemporaneidade. Logo, não pretendemos neste texto fazer críticas à escola, mas, a partir do que foi pesquisado, contribuir para possíveis reflexões, para aí sim "desconstruir" e reconstruir o que se sabe sobre os povos indígenas a partir da ótica do vídeo 0 perigo de uma única história. Acreditamos que, a partir das vivências interculturais e em busca de modificar o que se sabe, teremos possibilidade de aprendizagem por meio da educação intercultural.

6 Retirado de O perigo de uma única história, vídeo da escritora e contadora de histórias Chimamanda Ngozi Adichie. Essa nigeriana relata sua trajetória a partir de infância dela, mas trazendo diferentes leituras, escritas e conhecimentos. Em síntese, a escritora claramente aponta os "perigos" de conhecer uma determinada história e acreditar que ela se torna única somente por aquilo que ouviu e/ou leu, ou seja, seria como se outras histórias da mesma história não existissem. Logo, ao refletirmos sobre o vídeo, aproximamos ao que tange a Lei 11.645/08 (regulamenta a obrigatoriedade do Ensino da História e Cultura Afro-brasileira e Indígena na educação básica), a qual nos remete por meio da educação intercultural a oportunidade de contarmos "outras histórias", por vezes, escondidas e/ou totalmente distorcidas, para possivelmente não cometermos equívocos provocados por conta de uma "única história". 
Para melhor compreender a relevância da interculturalidade no contexto da Educação, na busca da fomentação atualizada sobre os povos indígenas, tomamos a cultura, por sua amplitude e dinamismo. Sucessivamente a especificidade de um grupo humano em relação a outro. Ao discorrer sobre o conceito de cultura, Geertz (1989) evidencia que ela está diretamente ligada ao conceito de Homem. Para ele, cada homem é formado por padrões culturais que os orienta nas relações com diversas pessoas, transformando-se em comportamentos de um grupo social específico no qual estamos inseridos.

Nessa perspectiva, para melhor contextualizarmos, tomamos a dança como uma das possibilidades de disseminação da cultura dentre os conteúdos presentes na área de Educação Física. Ao conhecer os Kaingang do Ivaí e, dentre suas práticas, a dança, o estudo possibilitou imergir em uma nova cultura, antes para nós desconhecida. Em decorrência disso, interpretamos e refletimos o objeto da pesquisa a partir do aspecto educacional intercultural:

a) para os Kaingang, o papel da dança vem na perspectiva da (re)criação da tradição como ritual na qual o mito e a história são ressignificadas e revitalizadas para educar o corpo e a identidade específica: a identidade Kaingang.

b) para o Fóg (não índio), a apreensão do "outro" por meio de sua arte (ritual revitalizado por eles). Nesse aspecto, a dança é potencialmente intercultural, quando nos aproxima do pressuposto antropológico de trabalho etnográfico, por meio do qual podemos transformar o estranho em familiar e o familiar em estranho.

Não obstante, considerando esses deslocamentos de sentido, por mais próximos que estejamos da cultura do "outro", jamais seremos um nativo, motivo pelo qual se dá a impossibilidade de o educador chegar diretamente à cultura por meio da dança, como pensávamos ingenuamente no início da pesquisa. Como aprendemos com Geertz (1989), mesmo por meio das vivências culturais, nossas interpretações sempre serão de segunda e terceira mãos, pois só o nativo faz a interpretação de primeira mão. Dessa maneira, destacamos o limite da dança, e ao mesmo tempo um iniciar para desenvolvê-la como mediadora de conhecimentos sobre os povos Kaingang.

Diante do dilema de estarmos sempre entre versões descoloridas do original e potências renovadoras desses sentidos vividos em primeira mão pelo nativo, optamos por retratá-las e refleti-las - ainda que embrionariamente - acerca da possibilidade de intervenção educacional pela interculturalidade. Essa postura se postula superadora em relação a outros conceitos, como transculturalismo, multiculturalismo, ou educação inter/multicultural. Na busca por princípios da interculturalidade na literatura (CANDAU, 2000, FLEURI, 2003, ANDRÉ, 2005), vimos que ela, entre outros aspectos, busca a interação entre culturas de uma forma mútua, favorecendo o seu convívio e integração. A relação está baseada no respeito pela diversidade e no enriquecimento recíproco de outras culturas.

Fleuri (2003) elucida que alguns autores referem-se ao adjetivo "intercultural" como a relação entre grupos folclóricos, mestiçagem ou mesmo elementos transversais presentes em distintas culturas. Porém, o mesmo autor amplia o conceito de interculturalidade e o define como uma forma de superar as barreiras culturais que nos separam do "outro", construindo uma predisposição para a leitura positiva, para uma multiplicidade cultural e social capaz de promover a reconstituição do próprio indivíduo. Apesar das diversas terminologias, considerase educação intercultural o conjunto de propostas educacionais e pedagógicas que têm 0 
interesse de estimular relações de respeito e integração entre diversos grupos socioculturais, dentro de uma perspectiva dialógica.

De acordo com o recente panorama de reconhecimento da interculturalidade como fator pedagógico importante, surgem novas propostas educativas ou revitalizam-se outras que tinham sido postas de lado, visando restaurar paradigmas metodológicos que auxiliem no desenvolvimento e aprendizagem do estudante (FLEURI, 2003). O mesmo autor ressalta a necessidade de se (re)pensar o papel do educador, já que ele deve estimular as diferenças entre indivíduos e seus contextos histórico, cultural e social visando à troca de informações em diferentes níveis organizacionais. E mais, o educador é um sujeito que se insere num processo de ensino-aprendizagem e dedica "particular atenção às relações e aos contextos que vão se criando" e, nesses contextos, a programação didática e o currículo terão função essencial na educação intercultural.

Porém, ao relacionar a interculturalidade à educação básica nos deparamos com alguns desafios a partir de novas relações interculturais que vêm crescendo gradativamente com mais ênfase no cenário mundial. Mas, por outro lado, a educação intercultural torna-se uma conceituação operacional.

Sob essa ótica, o ensino dos povos indígenas, tanto no passado como no presente, pode ser útil para superar as barreiras construídas por preconceitos culturais e pelo etnocentrismo, passando a representar uma perspectiva pedagógica para a alteridade, defendendo 0 respeito mútuo entre diferentes grupos. Dessa maneira, a perspectiva intercultural de educação implica em:

[...] mudanças profundas na prática educativa, de modo particular na escola. Pela necessidade de oferecer oportunidades educativas a todos, respeitando e integrando a diversidade de sujeitos e de seus pontos de vista. Pela necessidade de desenvolver processos educativos, metodologias e instrumentos pedagógicos que dêem conta da complexidade das relações humanas entre indivíduos e cultura diferentes. E pela necessidade de reinventar o papel e o processo de formação dos educadores (FLEURI, 2001, p. 56).

No fazer pedagógico dos professores indígenas de dança, buscamos elementos para o nosso próprio fazer. Situamos a escola como um dos canais de diálogo e a Educação Física como um dos interlocutores que olha os Kaingang do Ivaí na perspectiva da revitalização e ressignificação de suas tradições. Porém, ao utilizarmos tais conhecimentos, esperamos auxiliar na disseminação da cultura indígena para indígenas e não indígenas.

$E$, nesse processo, para compreender a educação intercultural se fez necessário entender primeiro este ato simbólico na dimensão entre os mais novos com os mais velhos, bem como entender as técnicas corporais presentes. Ao compreender a dança indígena, compreende-se as dimensões de cada gesto com este ato eficaz que ajuda na constituição da identidade. Neste sentido, nas relações dos mais velhos com os mais jovens, em busca de conhecimento de seus rituais e técnicas corporais, ela ocorreu por meio de uma educação tradicional. Hasse ${ }^{7}$, ao interpretar Mauss $(1974)^{8}$, reforça que uma técnica do corpo é um ato

7 HASSE, Manuela. Corpo, técnica e desenvolvimento: um problema humano e social. Texto apresentado em Provas de Agregação da disciplina Antropologia e História do Corpo, na Faculdade de Ciências da Motricidade. UTL/FMH, Lisboa, novembro de 2001.

8 MAUSS, Marcel. As Técnicas Corporais. In: LÉVI-STRAUSS, Claude. Sociologia e Antropologia, com uma introdução à obra de Marcel Mauss. Tradução de Lamberto Puccinelli. São Paulo: EPU, 1974. p.211-233. (Extraído do Journal de Psychologie, XXXII, n. 3-4, 15 de março-15 de abril de 1936. Comunicação apresentada à Société de Psychologie em 17 de maio de 1934). 
tradicional e eficaz, ou seja, não é mecânico, dessa forma, torna-se tradicional, porque ocorreu a transmissão de mão em mão, que passa de geração em geração (como, por exemplo, na geração atual, não ensinei meu filho, mas, futuramente, meu filho ou outra pessoa poderá pedir e possivelmente será lembrado). Para esse processo que supõe proximidade, quem poderia levantar conhecimentos sobre costumes de determinada época e/ou sobre as danças Kaingang do Ivaí? Com certeza, esse que é Kaingang, não sendo possível outro que não o seja.

Afinal, o processo de transmissão da dança no grupo Kakrēkin se desenrola com duração muito mais longa e com certa regularidade. Portanto, esse ato tradicional e eficaz é justamente importante porque ele não é um fazer mecânico e o mais importante nele é o efeito simbólico que traz. A técnica corporal, segundo Hasse ${ }^{9}$ (2001), precisa ser percebida nessa dimensão simbólica para ocorrer a educação intercultural. A eficácia do gesto compreende seu significado.

Nos pressupostos da educação intercultural não basta repassar conteúdos indígenas se eles são ensinados sem agregar os significados e conhecimentos culturalmente inscritos nessas práticas. Por isso buscamos compreender como os próprios atores se educam na e para as danças Kaingang da TI Ivaí. Ao ressignificarem danças ancestrais para apresentação aos seus e também ao outro (Fóg), esses atores nos fornecem pistas sobre aquilo que é inegociável (a lógica interna da atividade) e quais elementos estão sujeitos a mudanças. Sem esse diálogo, estaremos sujeitos (e sujeitando o conhecimento indígena) aos modos autoritários de expropriação da cultura.

\section{CONSIDERAÇÕES FINAIS}

Em nossa conclusão, a dança na TI Ivaí propiciou educação intercultural. A intervenção educacional, na perspectiva da educação intercultural, visa uma educação para o (re) conhecimento do "outro", para o diálogo entre os diferentes grupos sociais e culturais, ou seja, uma educação para a negociação cultural capaz de favorecer a construção de um projeto comum, pelo qual as diferenças sejam dialeticamente associadas.

Por isso também concluímos que esse grupo gestou uma educação intercultural que conserva e transforma a tradição, causando deslocamentos na cultura. A dança serve de contexto para os Kaingang do Ivaí fazerem educação intercultural com o outro, dentro e fora do seu próprio espaço. $\mathrm{O}$ ensino de uma dança prevendo a apresentação requer (re)pensar como 0 outro (Fóg) consegue assimilar a cultura Kaingang por meio da dança. Ao fazer isso o Kaingang do Ivaí reafirma-se, realimentando os códigos Kaingang perante sua própria TI, as outras terras e o Fóg. Mas, complementarmente, ao organizar um modo de dançar a ancestralidade compreensível ao outro, os integrantes do grupo Kakrēkin estão exercitando a alteridade.

Logo, a dança Kaingang do Ivaí apresenta-se através de diferentes demandas, possuindo caráter dinâmico e, consequentemente, em constante mudança. As danças nos remetem a essa característica móvel da cultura, especialmente quando a entendemos não apenas como um objeto em si, mas, também, em sua dimensão mediadora entre tradições, conhecimentos e práticas.

Por fim, sugerimos que a dança indígena presente na TI Ivaí, inserida no contexto das aulas-ensaios, pode se tornar um recurso importante na disseminação de conceitos e modos 
de fazer Kaingang. Dessa forma, ao constituir alteridade, merecem maior atenção por parte dos profissionais da área de Educação (Física) quando ainda elaboram-se grades curriculares que pouco ampliam o universo sociocultural dos alunos.

A Educação Física transmite conhecimentos da cultura corporal de forma sistematizada. Todavia, pouco se ensina a respeito de práticas corporais afro-indígenas em comparação com a matriz Europeia-Ocidental. Ademais, para a educação intercultural acontecer, não basta haver mudança somente nos conteúdos, mas na forma de abordagem, mudança de postura (conhecimento moral, racional) e nos métodos de ensino.

Não obstante a consideração de que os próprios Kaingang do grupo Kakrēkin são aqueles que guardam a efetiva relação entre eficácia técnica e simbólica da dança, postulamos que os conhecimentos das danças Kaingang podem servir de suporte para o professor desenvolver a temática indígena na educação básica, ao menos conforme expresso na Lei $11.645 / 08$.

\section{REFERÊNCIAS}

ADICHIE, Chimamanda Ngozi. 0 perigo de uma única história. Disponível em: <http://www. youtube.com/watch?v=06mbjTEsD58>. Acesso em: 16 out. 2014.

ANDRÉ, João Maria. Diálogo intercultural, utopia e mestiçagens. Coimbra: Ariadne, 2005.

BERGAMASCHI, Maria Aparecida; GOMES, Luana Barth. A temática indígena na escola: ensaios de educação intercultural. Currículo sem Fronteiras, v. 12, n. 1, p. 53-69, jan./abr. 2012.

BRASIL. Lei n. 11.645 de 10 de março de 2008. Nos estabelecimentos de ensino fundamental e de ensino médio, públicos e privados, torna-se obrigatório o estudo da história e cultura afro-brasileira e indígena. Diário Oficial da República Federativa do Brasil, Brasília, DF, 10 mar. 2008.

CANCLINI, Nestor Garcia. Culturas híbridas: estratégias para entrar e sair da modernidade. São Paulo: EDUSP, 2006.

CANDAU, Vera Maria. Interculturalidade e educação escolar. Rio de Janeiro: PUC-RJ, 2006.

CANDAU, Vera Maria. (Org.). Sociedade, educação e cultura(s): questões e propostas.

Petrópolis: Vozes, 2000.

FASSHEBER, José Ronaldo Mendonça. Etno-desporto indígena: a antropologia social e 0 campo entre os Kaingang. Brasília: Ministério do Esporte, 2010.

FAUSTINO, Rosângela Célia. Política educacional nos anos de 1990: o multiculturalismo e a interculturalidade na educação escolar indígena. 2006. 334 f. Tese (Doutorado) - Programa de Pós-Graduação em Educação, Departamento de Educação, Universidade Federal de Santa Catarina, Florianópolis, 2006.

FLEURI, Reinaldo Matias. Desafios à educação intercultural no Brasil. Educação, Sociedade \& Culturas, Porto, n. 16, p. 45-62, 2001.

FLEURI, Reinaldo Matias. Intercultura e Educação. Revista Grifos, Chapecó, n. 15, p. 16-47, maio 2003. 
FLEURI, Reinaldo Matias. Desafios à educação intercultural no Brasil. In: NANNI, A. L'educazione interculturale oggi in Itália. Brescia: EMI, 1998.

GRANDO, Beleni Saléte. Corpo e educação: as relações interculturais nas práticas corporais Bororo em Meruri-MT. 2004. 357 f. Tese (Doutorado) - Programa de Pós-graduação em Educação, Centro de Ciências da Educação, Universidade Federal de Santa Catarina, Florianópolis, 2004.

GEERTZ, Clifford. A interpretação das culturas. Rio de Janeiro: LTC, 1989.

HENNERICH, Juçara Elza. Aldeias Indígenas do Paraná: olhares de Guarani para Guarani. Guarapuava: Unicentro, 2007.

INSTITUTO SOCIOAMBIENTAL. Povos indígenas no Brasil. São Paulo, 2014.

LARA, Larissa Michelle. As danças no candomblé: corpo, rito e educação. Maringá: Eduem, 2008.

MAUSS, Marcel. Ensaios de Sociologia. 2. ed. Estudos 47. São Paulo: Perspectiva, 1999. (Título do original: Oeuvres, Les Editions de Minuit, 1968 e 1969). p.112-129.

MAUSS, Marcel. Sociologia e antropologia. São Paulo: Cosac, 2003.

MOTA, Lúcio Tadeu. (Org.). Diagnóstico etno-ambiental da terra indígena Ivaí-PR. Maringá: UEM, 2003.

MOTA, Lúcio Tadeu. As guerras dos índios Kaingang: a história épica dos índios Kaingang no Paraná (1769-1924). Maringá: Eduem, 2009.

MOTA, Lúcio Tadeu; ASSIS, Valéria Soares. Populações indígenas no Brasil: histórias, culturas e relações interculturais. Maringá: Eduem, 2008.

MOTA, Lúcio Tadeu; NOVAK, Éder da Silva. Os Kaingang do Vale do Rio Ivaí-PR: história e relações interculturais. Maringá, Eduem, 2008.

PIMENTEL, Giuliano Gomes de Assis; UEMA, Fábio Alexandre; OLIVEIRA, Amauri Aparecido Bassoli. Formação de lideranças e educação para o lazer na realidade indígena: relato de um diálogo multicultural. Educación Física y Deporte, Medellín, v. 32, p. 1255-1263, 2013.

RICHARDSON, Roberto Jarry. Pesquisa social: métodos e técnicas. São Paulo: Atlas, 2011.

TOMMASINO, Kimiye; FERNANDES, Ricardo Cid. Kaingang. Introdução. In: INSTITUTO SOCIOAMBIENTAL. Povos indígenas no Brasil. São Paulo: Instituto Socioambiental, 2003. Disponível em: http://pib.socioambiental.org/pt/povo/kaingang. 